\title{
Overshadowing not potentiation in taste aversion conditioning
}

\author{
PETER J. MIKULKA, ELIZABETH PITTS, and CHRISTINE PHILPUT \\ Old Dominion University, Norfolk, Virginia 23508
}

\begin{abstract}
Two experiments with rats examined the development of an odor (almond) aversion when that cue was compounded with a taste cue (saccharin and sucrose). Both studies found evidence of overshadowing; the almond aversion was reduced when conditioned in a compound. This finding contrasts with earlier reports of compound-cue potentiation of a less salient odor cue. These results are presented to indicate the need for a reexamination of the potentiation phenomenon.
\end{abstract}

In the overshadowing paradigm, two distinctive stimuli are combined and followed by a reinforcing event (US). If the stimuli are differentially salient for the organism, the typical outcome is that the less salient stimulus acquires little associative strength, that is, it is overshadowed, and the more salient cue becomes strongly associated with the US (e.g., Mackintosh, 1971; Pavlov, 1927; Revusky, 1971). In food aversion learning in rats, olfactory and visual cues are poorly associated (less salient) with toxicosis, but taste cues (more salient) are readily associated with illness (Garcia \& Koelling, 1966; Hankins, Garcia, \& Rusiniak, 1973). From an overshadowing perspective, it might be expected that when odor and taste cues are paired and followed by illness, the taste cue should overshadow the odor cue. However, recent studies have reported a reversal of the overshadowing effect: potentiation. Specifically, when the less salient odor cue is paired with a more salient taste cue and followed by toxicosis, the rat develops a stronger aversion to the odor cue than if the odor cue alone had been paired with toxicosis (Durlach \& Rescorla, 1980; Lorden, Kenfield, \& Braun, 1970; Rusiniak, Hankins, Garcia, \& Brett, 1979). Similar potentiation has been reported using visual and taste cues in rats (Galef \& Osborne, 1978) and in birds (Brett, Hankins, \& Garcia, 1976; Clarke, Westbrook, \& Irwin, 1979; Lett, 1980).

Potentiation is empirically and theoretically important because it is inconsistent with the literature and current accounts of compound-cue conditioning (e.g., Mackintosh, 1975; Rescorla \& Wagner, 1972). In light of the potential significance of potentiation, the present research was begun as an attempt to explore the parameters that affect potentiation. This resulted in five studies that failed to find any evidence of potentiation but produced reliable overshadowing. Although failures to replicate are rarely given much consideration, we felt that, given the importance of potentiation, evidence concerning its reliability is valuable. Below are presented two of the most straightforward examinations of potentiation.

\section{EXPERIMENT 1}

This experiment was prompted by the finding of Rusiniak et al. (1979, Experiment 3) that the degree of odor-cue potentiation is increased when the concentration of the compounded taste cue is increased. This study was not designed as a straightforward replication, but as an initial attempt to produce potentiation with parameter values typically used in this laboratory. Therefore, a number of parameters differed (e.g., twobottle test procedure, sucrose taste cue, reduced odor concentration, tap water) from those of Rusiniak et al.

\section{Method}

Subjects. The subjects were 40 naive female Sprague-Dawley albino rats, approximately 45-55 days old. They were individually housed and maintained with ad-lib access to Purina pellets throughout the experiment. The animals were kept on a $12: 12$ light-dark schedule (lights on at 6:00 a.m. and off at 6:00 p.m.). All training was conducted during the light phase between $8: 00$ and 10:00 a.m.

Training procedures. Upon arrival in the laboratory, the subjects were given 3 days of ad-lib access to tap water. Water deprivation was begun on the 4 th day and consisted of $30 \mathrm{~min}$ of daily water access. After 7 days on this pretraining schedule, the subjects had sufficiently stabilized their intakes to begin training.

This study used three levels of a taste cue $(0 \%, 4 \%$, and $16 \%$ sucrose solutions, w/w) combined with a $.2 \%$ solution ( $v / v)$ of Ann Page almond extract. Appropriate concentrations of the odor and taste cues were maintained when they were combined. On the single training day, each subject was allowed $30 \mathrm{~min}$ access to the appropriate training solution. An intraperitoneal injection at $.5 \%$ of body weight of either a $.6-\mathrm{M} \mathrm{LiCl}$ solution or isotonic saline was given within $15 \mathrm{~min}$ after completion of the solution access period.

The subjects were matched on pretraining water intake and assigned to one of the six experimental groups: A-S, $.2 \%$ almond solution followed by a saline injection $(n=7) ; A-L, .2 \%$ almond solution followed by an $\mathrm{LiCl}$ injection $(\mathrm{n}=7) ; \mathrm{AS}_{4}-\mathrm{S}, .2 \%$ almond $/ 4 \%$ sucrose compound solution and a saline injection $(\mathrm{n}=6) ; \mathrm{AS}_{4}-\mathrm{L}, .2 \%$ almond $/ 4 \%$ sucrose compound and an $\mathrm{LiCl}$ injection $(\mathrm{n}=7) ; \mathrm{AS}_{16}-\mathrm{S}, .2 \%$ almond $/ 16 \%$ sucrose compound and a saline injection $(\mathrm{n}=6) ; \mathrm{AS}_{16}-\mathrm{L}, .2 \%$ almond $/ 16 \%$ sucrose compound and an $\mathrm{LiCl}$ injection $(n=7)$.

Two recovery days ( $30 \mathrm{~min}$ of water per day) followed training. After the recovery days, the subjects were tested on 
3 consecutive days. On each test day, the subjects received $30 \mathrm{~min}$ access to two bottles, one containing water and the other containing a .2\% almond solution, a $4 \%$ sucrose solution, or a $16 \%$ sucrose solution. Each subject received all three test pairs, and the order of presentation was counterbalanced over the test days.

All mean comparisons included in this text employed the Newman-Keuls test and used an .05 alpha level.

\section{Results}

A simple analysis of variance was performed on the training day intakes. This indicated that consumption of the novel solutions was equivalent across groups $[\mathrm{F}(5,34)<1]$, with group mean intakes varying from $9.4 \mathrm{ml}$ to $11.3 \mathrm{ml}$.

A 2 (drug: $\mathrm{LiCl}$, saline) by 3 (taste cue: $0 \%, 4 \%$, $16 \%$ sucrose) factorial analysis of variance was performed on each of the three preference tests. Table 1 presents the preferences for the test solutions over water during the three tests.

The 2 by 3 analysis of variance of the almond-water test yielded significant main effects for drug $[\mathrm{F}(1,34)=$ $92.5, \mathrm{p}<.01]$, taste cue $[\mathrm{F}(2,34)=10.8, \mathrm{p}<.05]$, and their interaction $[F(2,34)=6.7, p<.05]$. All the LiCl-poisoned groups showed a significantly reduced preference for almond when compared to the saline control groups. Range tests indicated that the almond aversion of the $\mathrm{AS}_{16}-\mathrm{L}$ group was less than that seen in the A-L and $\mathrm{AS}_{4}-\mathrm{L}$ groups, which did not differ from each other. This indicates that overshadowing was present when the $16 \%$ sucrose cue was compounded with almond.

Similar factorial analyses of the $4 \%$ sucrose-water and $16 \%$ sucrose-water tests found significant effects for drug, taste cue, and their interaction. Range tests performed on these effects indicated that there was no aversion to sucrose in the A-L group, which, like the saline-injected groups, showed uniformly strong preferences for both sucrose solutions. However, the $\mathrm{AS}_{4}-\mathrm{L}$ and $\mathrm{AS}_{16}-\mathrm{L}$ groups both showed a reduced preference

Table 1

Means and Standard Deviations of the Percent Preference of the Training Cue in Two-Bottle Tests

\begin{tabular}{|c|c|c|c|c|c|c|}
\hline \multirow[b]{3}{*}{ Group } & \multicolumn{6}{|c|}{ Test Solution } \\
\hline & \multicolumn{2}{|c|}{$\begin{array}{l}\text { Almond } \\
\text { vs. Water }\end{array}$} & \multicolumn{2}{|c|}{$\begin{array}{l}4 \% \text { Sucrose } \\
\text { vs. Water }\end{array}$} & \multicolumn{2}{|c|}{$\begin{array}{l}16 \% \text { Sucrose } \\
\text { vs. Water }\end{array}$} \\
\hline & Mean & SD & Mean & SD & Mean & SD \\
\hline$A-S$ & 34.3 & 24.4 & 78.1 & 18.6 & 75.3 & 20.1 \\
\hline A-L & 4.9 & 6.2 & 78.9 & 30.0 & 69.4 & 21.6 \\
\hline $\mathrm{AS}_{4}-\mathrm{S}$ & 70.0 & 18.6 & 71.5 & 20.2 & 81.5 & 14.2 \\
\hline $\mathrm{AS}_{4}-\mathrm{L}$ & 5.1 & 6.9 & 46.0 & 27.1 & 29.7 & 16.8 \\
\hline $\mathrm{AS}_{16}-\mathrm{S}$ & 68.0 & 20.6 & 84.3 & 7.3 & 74.8 & 19.8 \\
\hline $\mathrm{AS}_{16}-\mathrm{L}$ & 25.9 & 11.3 & 24.4 & 6.7 & 23.6 & 16.1 \\
\hline
\end{tabular}

Note-Values are expressed as (training cue in milliliters)/(training cue in milliliters + water in milliliters). A preference ratio approaching 0 indicates $a$ strong avoidance toward the training cue; a preference ratio approaching 100 indicates a strong preference for the training cue. for both sucrose concentrations. On the $4 \%$ sucrose test, the $\mathrm{AS}_{16}$-L group showed a stronger aversion than the $\mathrm{AS}_{4}-\mathrm{L}$ group, but they evidenced equivalent aversions on the $16 \%$ sucrose test.

\section{Discussion}

The findings of this study indicate that when almond is compounded with the $16 \%$ sucrose taste cue, the aversion to almond is overshadowed when compared to that seen in the almond-only group. The $4 \%$ sucrose cue apparently did not interfere with the development of the almond aversion. It is interesting to note that the A-L group demonstrated a strong almond aversion despite the weak almond concentration. In fact, the A-L subjects showed an almost complete avoidance of the almond solution. The two-bottle preference test may have been responsible for the magnitude of this effect, since it is more sensitive than the one-bottle tests (Dragoin, McCleary, \& McCleary, 1971). Given this strong aversion, a ceiling effect may have obscured a potentiation effect in the $\mathrm{AS}_{4}-\mathrm{L}$ subjects. However, this is unlikely, because the results reported by Rusiniak et al. (1979) predict increasing potentiation with increasing taste (saccharin) concentration and the present result is in the opposite direction.

On the sucrose tests, the saline-injected animals evidenced strong sucrose preferences, as did the A-L group. In contrast, both the sucrose-poisoned groups $\left(\mathrm{AS}_{4}-\mathrm{L}\right.$ and $\left.\mathrm{AS}_{16}-\mathrm{L}\right)$ avoided the sucrose solutions and there was a tendency for the $\mathrm{AS}_{16}-\mathrm{L}$ group to show the strongest avoidance. Since this $\mathrm{AS}_{16}-\mathrm{L}$ group showed a clear overshadowing of the odor cue, it would be anticipated that more associative strength would accrue to the taste cue. However, this taste aversion was statistically stronger only on the $4 \%$ test.

\section{EXPERIMENT 2}

The failure to find potentiation in Experiment 1 using sucrose, a weaker almond concentration (.2\% almond), and a two-bottle test prompted a closer replication of the Rusiniak et al. (1979) study. A one-bottle test, a $2 \%$ almond concentration, and two saccharin concentrations chosen from their potentiation function (Experiment 3) were used. Added to the saccharin concentrations were two sucrose concentrations that provided a comparison with our first experiment.

\section{Method}

Subjects. The subjects were 30 naive female Sprague-Dawley albino rats aged 45-55 days. All housing and general maintenance conditions were the same as those in Experiment 1.

Training procedures. After 3 days of ad-lib access to distilled water, the subjects were placed on a daily 20 -min waterdeprivation pretraining schedule for 14 days. On Day 15, a single training session occurred. Distilled water was used for water access and in all training solutions.

Based on the last pretraining intakes, the subjects were matched and assigned to one of the five experimental groups: Group A received a $2 \%$ almond (v/v) solution; Group $\mathrm{AS}_{4}$ received $2 \%$ almond combined with $4 \%$ sucrose; Group $\mathrm{AS}_{32}$ received $2 \%$ almond combined with $32 \%$ sucrose; Group AX. $\mathbf{A X}_{16}$ received $2 \%$ almond with $.016 \%$ saccharin; Group $\mathrm{AX}_{.1}$ received $2 \%$ almond with $.1 \%$ saccharin. Fifteen minutes after a single 20-min access to the appropriate solution, all subjects received an intraperitoneal injection of $.32 \mathrm{M} \mathrm{LiCl}$ at $1 \%$ body weight. Two recovery (water-only) days followed. On the next day, the subjects were given $20 \mathrm{~min}$ access to one bottle containing a $2 \%$ almond solution. 
Table 2

Means and Standard Deviations of Fluid Intakes for the Training Day, the Almond Test, and Compound Test

\begin{tabular}{lrrrrrr} 
& \multicolumn{2}{c}{ Training Day } & & \multicolumn{2}{c}{ Almond Test } & \\
\cline { 2 - 3 } Group & Mean & SD & & Mean & SD & \%* \\
\hline A & 11.3 & 1.4 & & 4.8 & 2.1 & 48 \\
AS $_{4}$ & 8.7 & 2.9 & & 6.7 & 1.2 & 63 \\
AS $_{32}$ & 6.0 & 1.4 & & 8.0 & 1.7 & 68 \\
AX $_{.016}$ & 11.1 & 1.7 & & 4.7 & 2.6 & 42 \\
AX.1 $_{.1}$ & 7.2 & 1.2 & & 9.2 & 2.2 & 85 \\
\hline
\end{tabular}

*Test intakes as a percentage of the last pretraining day water intakes.

\section{Results}

A simple analysis of variance performed on the training day intakes yielded a significant groups effect $[F(4,25)=10.2, p<.001]$. Range comparisons indicated a differential neophobia. The $\mathrm{A}$ and $\mathrm{AX}_{.016}$ groups had equivalent high almond intakes, whereas the $\mathrm{AX}_{.1}$ and $\mathrm{AS}_{32}$ groups were not different and consumed the least. The $\mathrm{AS}_{4}$ group was intermediate between these two groupings and was different only from the $\mathrm{AS}_{32}$ group.

A simple analysis of variance performed on the almond intakes during the almond test yielded a significant groups effect $[F(4,25)=5.4, p<.005]$. Mean comparisons indicated two major groupings: The $\mathrm{A}$ and $\mathrm{AX}_{.016}$ groups had the lowest almond intakes, and the greatest intakes were found in the $\mathrm{AX}_{.1}$ and $\mathrm{AS}_{32}$ groups. The $\mathrm{AS}_{4}$ group was intermediate and not different from either grouping.

Almond intakes were also converted to a percentage of the final pretraining day water intakes (this index was employed by Rusiniak et al., 1979). A simple analysis of variance performed on this index yielded the same results, with the exception that the $\mathrm{AS}_{32}$ group was not different from the $\mathrm{AS}_{4}$ group but was intermediate between the $\mathrm{AX}_{.1}$ group and the $\mathrm{AX}_{.016}$ and $\mathrm{A}$ groups. Both analyses indicate that the odor cue was clearly overshadowed by the higher saccharin concentration, and the pattern of findings suggests a trend toward a reduction in almond aversion with increasing taste concentration.

\section{Discussion}

The neophobia found on the training day when the more concentrated saccharin and sucrose cues were compounded with almond was comparable to that reported by Rusiniak et al. (1979). They found a significant neophobia with saccharin concentrations of $.05 \%$ and $.2 \%$, whereas the present study found neophobia in the $.1 \%$ saccharin group. Both found no evidence of neophobia when either $.0125 \%$ or $.016 \%$ saccharin was paired with almond. However, despite the neophobic response, all subjects in the present study drank at least $4 \mathrm{ml}$ of the training solution.

Examination of the almond test intakes indicated a clear overshadowing of the odor cue when conditioned in compound with the highest sucrose or saccharin concentrations. No evidence of potentiation was observed. Rusiniak et al. (1979) reported potentiation of the odor aversion when combined with a $.0125 \%$ saccharin solution and a greatly enhanced odor aversion when $.05 \%$ and $.2 \%$ saccharin cues were compounded with almond. In the present study, the $.016 \%$ saccharin subjects were equivalent to the A subjects in odor aversion, whereas the $.1 \%$ saccharin subjects showed a weak odor aversion, overshadowing instead of potentiation. Although the initial training intakes were comparable to those of Rusiniak et al. (1979), the test results reversed their findings.

\section{GENERAL DISCUSSION}

The present research found that an olfactory cue is readily overshadowed by a salient taste cue. Specifically, when the more concentrated taste cues were used, the almond odor aversion was negligible. These results are in contrast with the finding of potentiation and its enhancement with increased taste intensity. In a related study, Braveman (1975) exposed guinea pigs to saccharin-sweetened red water. Saccharin concentrations of $.05 \%, .15 \%$, and $.45 \%$ were combined with red water. Although there was no red-water/illness control group, none of the saccharin-compounded groups showed any aversion to red water. Again, there was no evidence of potentiation or of a graded intensity effect. The taste cue simply overshadowed the visual cue. In a second experiment, subjects familiarized with saccharin prior to compound condition, a process that reduces taste salience, showed an aversion to red water.

Recently, Bouton and Whiting (Note 1), in a series of six experiments using taste and odor cues in rats, repeatedly found overshadowing and no evidence of potentiation. In one study, they carefully replicated the within-subjects compound design of Durlach and Rescorla (1980) and failed to find potentiation.

Unfortunately, the present findings do not clarify the factors responsible for potentiation. Further, an examination of the studies reporting potentiation yields considerable parametric diversity but does not point to any methodological key that might account for the divergence of findings. What is clear about these results is that potentiation is not as robust and reliable an effect as the literature suggests. Given the importance of potentiation, a determination of the critical parameters controlling potentiation/overshadowing is essential so that the phenomenon can be placed within current compound conditioning formulations.

Although failures to replicate are generally uninteresting, the present data have a theoretical impact, since several authors are again suggesting that taste aversion learning is an exceptional process. In essence, organisms are selectively prepared to learn that distal cues (e.g., odor, color) predict gastric consequences when a salient gustatory cue is present (Galef \& Osborne, 1978; Rusiniak et al., 1979). Although there may be an intrinsic appeal to the notion that naturally occurring distal cues are "marked" or potentiated by a proximate gustatory cue (Clarke et al., 1979), a more parsimonious position is that taste aversion learning is consistent with the general laws of learning (see Logue, 1979). Whether this position is ultimately substantiated, the present taste aversion findings, coupled with those of Braveman (1975) and Bouton and Whiting (Note 1), fit well within the larger overshadowing literature, in which cues compete for attention and salient cues overshadow less salient cues (e.g., Mackintosh, 1975; Rescorla \& Wagner, 1972). In the present context, the development of an odor aversion in rats is overshadowed by the presence of a concentrated taste cue.

\section{REFERENCE NOTE}

1. Bouton, M. E., \& Whiting, M. R. A comparison of odortaste and taste-taste compounds in toxiphobia conditioning. Paper presented at the meeting of the Eastern Psychological Association, Baltimore, Maryland, 1982.

\section{REFERENCES}

Braveman, N. Relative salience of gustatory and visual cues in the formation of poison-based food aversions by guinea pigs (Cavia porcellus). Behavioral Biology, 1975, 14, 189-199. 
Brett, L. P., Hankins, W. G., \& Garcia, J. Prey-lithium aversions. III. Buteo hawks. Behavioral Biology, 1976, 17, 87-98.

Clarke, J. C., Westbrook, R. F., \& Irwin, J. Potentiation instead of overshadowing in the pigeon. Behavioral and Neural Biology, 1979, 25, 18-29.

Dragoin, W., McCleary, G. E., \& McCleary, P. A. A comparison of two methods of measuring conditioned taste aversions. Behavior Research Methods \& Instrumentation, 1971, 3, 309-310.

Durlach, P. J., \& Rescorla, R. A. Potentiation rather than overshadowing in flavor-aversion learning: An analysis in terms of within-compound associations. Journal of Experimental Psychology: Animal Behavior Processes, 1980, 6, 175-187.

Gale F, B. G., JR., \& OsBorne, B. Novel taste facilitation of the association of visual cues with toxicosis in rats. Journal of Comparative and Physiological Psychology, 1978, 92, 907-916.

Garcia, J., \& Koelling, R. A. Relation of cue to consequence in avoidance learning. Psychonomic Science, 1966, 4, 123-124.

Hankins, W. G., Garcia, J., \& Rusiniak, K. W. Dissociation of odor and taste in baitshyness. Behavioral Biology, 1973, $8,407-419$.

LETT, B. T. Taste potentiates color-sickness associations in pigeons and quail. Animal Learning \& Behavior, 1980, 8, 193198.

Logue, A. W. Taste aversion and the generality of the laws of learning. Psychological Bulletin, 1979, 86, 276-296.

Lordon, J. F., Kenfield, M., \& BraUn, J. J. Response suppression to odors paired with toxicosis. Learning and Motivation, $1970,1,391-400$.

Mackintosh, N. J. An analysis of overshadowing and blocking. Quarterly Journal of Experimental Psychology, 1971, 23, 118125.

Mackintosh, N. J. A theory of attention: Variations in the associability of stimuli with reinforcement. Psychological Review, 1975, 82, 276-298.

Pavlov, I. P. Conditioned reflexes. London: Oxford University Press, 1927.

Rescorla, R. A., \& Wagner, A. R. A theory of Pavlovian conditioning: Variations in associability of stimuli with reinforcement. In A. Black \& W. F. Prokasy (Eds.), Classical conditioning II: Current theory and research. New York: AppletonCentury-Crofts, 1972.

REVUSKY, $\mathbf{S}$. The role of interference in association over a delay. In W. K. Honig \& P. H. R. James (Eds.), Animal memory. New York: Academic Press, 1971.

Rusiniak, K. W., Hankins, W. G., Garcia, J., \& Brett, L. P. Flavor-illness aversions: Potentiation of odor by taste in rats. Behavioral and Neural Biology, 1979, 25, 1-17.

(Received for publication July 19, 1982.) 